\title{
EDITORIAL POLICY
}

ASTIN Bulletin was founded in 1958 as a journal providing an outlet for actuarial studies in non-life insurance. In the late 1980's the journal extended its scope to encompass the study of financial risk in insurance (AFIR). In 2007 the journal was established as the journal of the International Actuarial Association (IAA) and encompasses all of the scientific sections of the IAA.

ASTIN Bulletin publishes papers that are relevant to any branch of actuarial science and insurance mathematics. Papers should be quantitative and scientific in nature, and might draw on theory and methods developed in any branch of the mathematical sciences including actuarial mathematics, statistics, probability, financial mathematics and econometrics.

The journal welcomes papers that present significant and original theoretical developments and papers that present significant and original applications of mathematical, statistical or econometric theory to problems arising in insurance, pensions and finance. We especially welcome papers opening up new areas of interest to the international actuarial profession as well as papers that describe open problems that have arisen in practice.

\section{INDEXING}

ASTIN Bulletin is abstracted and indexed in the Social Sciences Citation Index, the Science Citation Index Expanded, the CompuMath Citation Index, and Current Contents/Social \& Behavioural Sciences; MathSciNet; Zentralblatt MATH; Scopus; CrossRef; ISI Links.

\section{PRIZES}

Papers published in ASTIN Bulletin are eligible for the award of the following prizes:

The Charles A. Hachemeister Prize: Papers eligible for the prize include articles, and/or invited papers published in ASTIN Bulletin, in addition to papers and Speakers' Corner papers presented at the ASTIN or AFIR Colloquium, in the calendar year prior to the prize award. Papers presented at an IAA Congress are also eligible for this award. Papers will be judged by a specifically appointed committee of the Casualty Actuarial Society. Emphasis will be placed on the paper's impact for North American actuaries and practicality of application.

The Bob Alting von Geusau Memorial Prize (sponsored by the AFIR Section of the IAA): Papers eligible for the prize include articles and/or invited papers published in ASTIN Bulletin with financial risk as a significant component of the work.

\section{SUBSCRIPTION AND BACK ISSUES}

Subscription price: 80 Euro.

Payments should be sent to Peeters, Bondgenotenlaan 153, B-3000 Leuven, Belgium.

To place your order or make an inquiry please contact: Peeters, Journals Department, Bondgenotenlaan 153, B-3000 Leuven, Belgium or e-mail: peeters@peeters-leuven.be

Orders are regarded as binding and payments are not refundable.

Subscriptions are accepted and entered by the volume. Claims cannot be made 4 months after publication or date of order, whichever is later.

\section{INDEX TO VOLUMES 1-27}

The Cumulative Index to Volumes 1-27 is also published for ASTIN by Peeters at the above address and is available for the price of 80 Euro. 
THE INTERNATIONAL ACTUARIAL ASSOCIATION

www.actuaries.org

Office Bearers

President

Katsumi Hikasa

President-elect

Paul N. Thornton

Immediate Past President

David G. Hartman

Secretary General

Yves Guérard

ASTIN Chairman

AFIR Chairman

Harry H. Panjer

IACA Chairman

Jean Berthon

IAAHS Chairman

Hideyuki E. Yoshida

PBSS Chairman

Emile J. Stipp

AWF Chairman

Christopher D. Daykin

LIFE Chairman

Edward J. Levay

Kurt Wolfsdorf

None of the International Actuarial Association (IAA), the Sections of the IAA, or PEETERS s.a. is responsible for statements made or opinions expressed in the articles, criticisms and discussions published in ASTIN Bulletin. 